\title{
Defensins and their role in the maintenance of the oral cavity homeostasis - a literature review
}

\author{
ZUZANNA ŚLEBIODA ${ }^{1}$, ELŻBIETA SZPONAR ${ }^{l}$, ANNA KOWALSKA ${ }^{2}$
}

1Department of Oral Mucosa Diseases, Poznan University of Medical Sciences, Poland

${ }^{2}$ Institute of Human Genetics in Poznan, Polish Academy of Sciences, Poland

\begin{abstract}
The maintenance of the local and systemic homeostasis in the human body depends on several specific and non-specific protective mechanisms. An important and one of the oldest elements of the innate, non-specific immunity in multicellular organisms are the defensins - very active, antimicrobial peptides. This review focuses on the structure and the properties of $\alpha, \beta$ and $\theta$ defensins and their biological role with a special emphasis on the oral environment. Antibacterial, antiviral and antifungal activity of the defensins, their influence on the immune response modulation in the presence of certain pathogens and the impact of their variable expression on the development of systemic diseases are discussed in this paper. We also presented the defensins' expression sites in the oral cavity, physiologic and pathologic conditions, where the modulated defensins' expression plays an important role and the potential options for the defensin use in the treatment of selected oral cavity diseases.
\end{abstract}

Key words: defensins, antimicrobial peptides, oral cavity diseases, oral mucosa, innate immunity.

(Centr Eur J Immunol 2013; 38 (1): 111-117)

\section{Introduction}

The oral mucosa acts as a barrier between the external and internal environment of the human body. Since the oral cavity is the initial part of the gastrointestinal tract, it has been constantly exposed to various pathogenic microorganisms and other, physical and chemical irritants, including the pressure, $\mathrm{pH}$ and temperature fluctuations. With time, several innate and acquired protective mechanisms were developed in humans in order to maintain the local and systemic homeostasis in the body. The important and one of the oldest elements of the innate, non-specific immunity in multicellular organisms are the defensins - very active, small proteins characterized by antimicrobial properties [1-4]. Defensins, which present antibacterial, antiviral and antifungal activity, are being produced in various tissues and cells of the gastrointestinal, the respiratory and the urogenital tracts $[2,3,5]$. These proteins were detected in neutrophils and blood platelets, saliva, urine and serum, while their intraoral expression was found in the periodontal tissue, the oral mucosa and the salivary glands
[2-4]. Their expression occurs either constantly or after the previous stimulation with the bacterial lipopolysaccharides and inflammatory mediators, which was confirmed in many in vitro and in vivo observations $[1,4,6]$. Depending on the type, defensins manifest various levels of antimicrobial activity and several immunomodulating properties: they stimulate the immune system by increasing the chemotactic activity of monocytes and T-lymphocytes and induce IL-8 production. They also participate in tissue healing and fibrynolysis $[5,7,8]$. Due to their multidirectional activity, defensins act as the first line of the defense against pathogens and they help to maintain the equilibrium of commensal flora in the organism [9]. The role of defensins in pathologic conditions of the oral cavity raises large interest, but so far it remains not clearly defined and understood.

\section{Defensins - structure and types}

The research on defensins was started on 1956, when Skarnes and Watson detected a bacteriocidal leukin and

Correspondence: Zuzanna Ślebioda, Department of Oral Mucosa Diseases, Poznan University of Medical Sciences, Bukowska 70, 60-812 Poznan, Poland, tel. +48 6185470 38, e-mail: zuzia_slebioda@o2.pl 
Hirsch described the presence of a phagocytine, another antibacterial peptide in polynuclear cells of rabbit $[2,3]$. Up to the 80-ties the term "CAP" (cationic antimicrobial peptides) was used to describe that sort of compounds and the name "defensins" was introduced after sequencing the substances in humans and rabbits in 1985 and it has been used up to now [3].

Defensins are highly cationic proteins $3-5 \mathrm{kDa}$ in size, formed by 20 to 40 aminoacids. They contain 6 atoms of cysteine, which form a characteristic, three-disulfidebonded secondary structure [10-12]. The presence of the sulfide bridges determines the antimicrobial properties of these peptides. Three groups of defensis have been described so far. They include $\alpha$-, $\beta$ - and $\theta$-defensins, in humans however only the first two groups are present (Table 1) [2, 8, 13].

The affiliation of the compound to a particular defensin group depends on the sulfide bridge localization. The $\alpha$-defensin group is comprised of 12 substances: HNP (human neutrophil peptide) 1-4, HD (human defensin) 5-6, NP (neutrophil peptide) 1, 5, criptidin 3, 4 and RMAD (rhesus macaque myeloid $\alpha$-defensin) 3,4 . The group of $\beta$-defensins consists of 25 substances, including: HBD (human $\beta$-defensin) $1-4$, SBD (sheep $\beta$-defensin) 1-2, TAP (tracheal antimicrobial peptide), LAP (lingual antimicrobial peptide), EBD (enteric $\beta$-defensin), BNBD (bovine neutrophil $\beta$-defensin) 1-13, PBD (porcine $\beta$-defensin) 1-2 and mBD

Table 1. Defensin classes and their distribution

\begin{tabular}{|c|c|c|c|}
\hline \multicolumn{2}{|c|}{ Group Name } & \multirow{2}{*}{$\begin{array}{l}\text { Organism } \\
\text { Humans }\end{array}$} & \multirow{2}{*}{$\begin{array}{l}\text { Location } \\
\text { Placenta, intestinal mucosa, uterine cervix }\end{array}$} \\
\hline$\alpha$ & HNP 1-3 & & \\
\hline & HNP 4 & Humans & Neutrophils \\
\hline & HD 5 & Humans & Salivary glands, stomach, small and large intestine, female reproductive organs, urethra, milk \\
\hline & HD 6 & Humans & Salivary glands, stomach, small and large intestine, urethra, milk \\
\hline & NP 1 & $\begin{array}{l}\text { Mice, rats, } \\
\text { guinea pigs, rabbits }\end{array}$ & Paneth cells \\
\hline & NP 5 & $\begin{array}{l}\text { Humans, mice, rats } \\
\text { guinea pigs, rabbits }\end{array}$ & Paneth cells \\
\hline & criptidin 3,4 & $\begin{array}{l}\text { Mice, rats, guinea } \\
\text { pigs, rabbits }\end{array}$ & Paneth cells \\
\hline & RMAD 3, 4 & Monkeys & Phagocytic cells, intestines \\
\hline \multirow[t]{13}{*}{$\beta$} & HBD 1-3 & Humans & $\begin{array}{l}\text { Oronasal mucosa, salivary glands, plasma, stomach, large and small intestine, skin, eyes, } \\
\text { mammalian glands, kidneys, urine }\end{array}$ \\
\hline & HBD 4 & Humans & Testicles, stomach \\
\hline & SBD 1 & Goats, sheep & $\begin{array}{l}\text { Nasal mucosa, salivary glands, plasma, stomach, large and small intestine, skin, eyes, } \\
\text { mammalian glands, kidneys }\end{array}$ \\
\hline & SBD 2 & & Small and large intestines, reproductive organs, lungs \\
\hline & TAP & \multirow{7}{*}{ Cattle } & Trachea, alveolar macrophages \\
\hline & LAP & & Tongue, oesophagus \\
\hline & EBD & & Small and large intestines \\
\hline & $\begin{array}{l}\text { BNBD } \\
1-3,6-11\end{array}$ & & Neutrophils \\
\hline & BNBD 4 & & Trachea, lungs, spleen, small and large intestines, alveolar macrophages, neutrophils \\
\hline & BNBD 5 & & Alveolar macrophages, neutrophils \\
\hline & BNBD 12,13 & & Neutrophils, trachea, lungs, small and large intestines \\
\hline & PBD $1-2$ & Pigs & Oral mucosa, respiratory ducts \\
\hline & $\operatorname{mBD} 1$ & Mice & Lungs, kidneys, heart \\
\hline \multirow[t]{2}{*}{$\theta$} & retrocyclin 1,2 & Mammals & Leukocytes \\
\hline & RTD 1-3 & Monkeys & Leukocytes, bone marrow \\
\hline
\end{tabular}


(mice $\beta$-defensin) 1 . The $\theta$-defensins, which include retrocyclin 1, 2 and RTD (rhesus $\theta$-defensin) 1-3, are produced by the mammals (e.g. by Rhesus) but not by the humans $[4,5,11,14]$.

Defensin encoding genes are localized on chromosome 8 in the region 8 p21-23. The number of genes manifests some fluctuations, depends on population studied. Leukocytic $\alpha$-defensins are encoded by the genes composed of 3 exons, while the other defensin encoding genes consist of 2 exons only. Moreover, the $\beta$-defensin encoding genes can be divided into small intron genes $(2 \mathrm{~kb})$, which encode the compounds with inducible expression (e.g. HBD-2) and the genes with a large intron $(10 \mathrm{~kb})$, which encode constantly expressed defensins, like HBD-1 [1].

\section{Biological role of defensins in the human body}

Defensins manifest a broad spectrum of antimicrobial activity, which is illustrated on Fig. 1 [4, 11, 12].

They exhibit antibacterial properties against Gram-positive (Staphylococcus aureus) and Gram-negative (Escherichia coli, Pseudomonas aeruginosa) bacteria [3, 4, 12] and inhibit the development of pathogenic, enucleated viruses including Herpes (HSV-1 and HSV-2) viruses, cyto- megalovirus, influenza virus and HPV [4, 15]. They act against HIV directly by interacting with the virus's capsule and indirectly by modulating the virus co-receptors' activity on the surface of peripheral blood mononuclear cells (PBMC) [16, 17]. Moreover, defensins reveal antifungal and antiparasitic properties against Candida albicans, Plasmodium and Leishmania $[2,11]$. One of their antimicrobial mechanisms leads to the apoptosis of external, microbial cells: the defensin's connection with the cell membrane of attacked bacteria is followed by the cell internalization, endocytosis and finally by its apoptosis [2]. Apart from the direct antimicrobial activity, defensins reveal the potential to modify the host immunity. They induce the chemotaxis of immature dendritic cells (HNP-1, HBD 1-3), mast cells (HBD 2) and T-lymphocytes (HBD 2, HNP-1), stimulate the production of cytokines like TNF- $\alpha$ and IL-1 $\beta$ (HNP-1) and activate the complement system $[7,11,12]$. Moreover, they neutralize bacterial endotoxin and participate in wound healing and fibrinolysis $[2,11]$.

Defensins were detected in various cells and tissues of the human body both in the state of health and the disease. Pathologic conditions in the human body modify the defensins' expression in tissues. Therefore in particular states the elevated or reduced concentration of these compounds may be detected. Cystic fibrosis $(\mathrm{CF})$ and adult res-

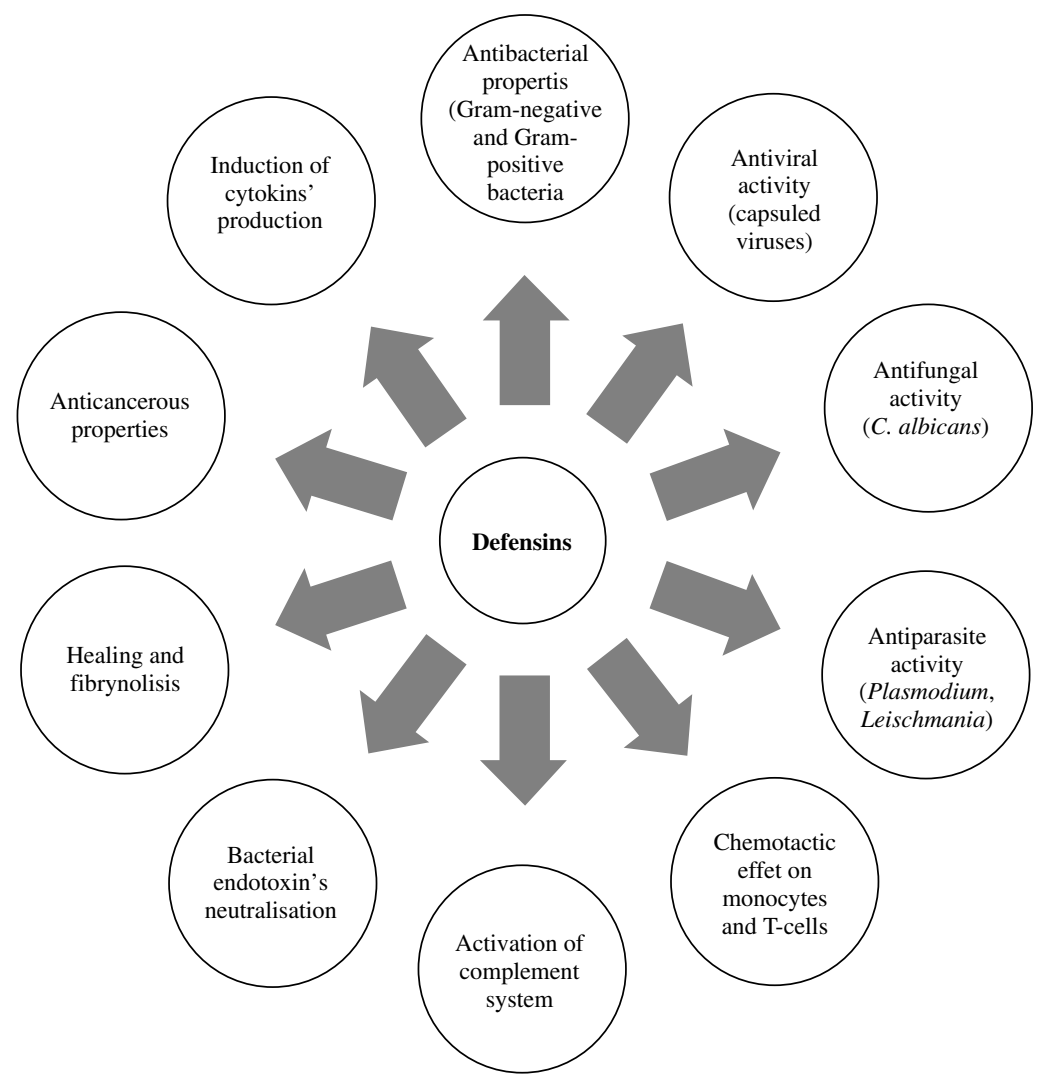

Fig. 1. Biological role of defensins in mammals 
piratory distress syndrome (ARDS) are characterized by the decreased $\beta$-defensins' and increased $\alpha$-defensin' concentrations [18-20]. In Crohn's disease the decreased concentrations of HD 5 and 6 appear in ileo-caecalis location of pathologic lesions, while the HBD 2 concentration becomes decreased in colonic localization of the lesions. Meanwhile in ulcerative colitis the expression of HBD 2 raises [19, 21, 22]. It was found that the risk of Crohn's disease development is associated with genetic polymorphism characterized by the reduced number of HBD-2 gene copies in human genome [23]. It atopic dermatitis this defensin's concentration in diseased tissues decreases, while in simple psoriasis it becomes elevated. In keratinocytes of psoriatic patients also the expression of HBD-1 rises [18, 19].

While the HBD 1 expression in the human body occurs constantly, the transcription of the HBD 2 gene becomes induced in the presence of cytokines like IL-1 $\beta$ and TNF- $\alpha$, bacterial lypopolysaccharides and fungi [4, 24]. HBD-2 concentration therefore elevates in various inflammatory conditions. Also the HBD-3 expression is stimulated by TNF- $\alpha$, IFN- $\gamma$, Gram-positive and Gram-negative bacteria [4].

\section{The expression and the role of defensins in the oral cavity}

In the oral environment potentially pathogenic microorganisms coexist with the harmless, commensal bacteria. Innate and acquired immune mechanisms help to maintain the balance between the particular species in the oral cavity and to prevent the development of the disease. Defensins' expression occurs in various sites of the mouth, e.g. in the periodontal tissue, the oral mucosa and the salivary glands. Defensins were detected in saliva and crevicular fluid and manifest flexible activity potential against oral cavity pathogens $[6,25,26]$.

$\alpha$-defensins are produced mainly by neutrophils. In the oral cavity of healthy persons they can be detected in junctional epithelium and in crevicular fluid [27]. $\beta$-defensins (HBD 1-3) are present in a normal, startified, squamous epithelium of the oral mucosa. The expression of HBD-1 and '' mRNA occurs in stratum spinosum, while the products may be detected in higher levels of epithelium in stratum granulosum and corneum $[12,27]$. Normally the HBD-3 expression is found mainly in basal cell layer and in Langerhans and Merkel cells, while during the inflammation this defensin may be also expressed in more superficial layers of the epithelium [17]. Like in the other human body regions, the expression of HBD-1 in the oral mucosa cells occurs constantly. The basal HBD-2 concentration in the oral epithelium is relatively low, but increases rapidly in the presence of cytokines (TNF- $\alpha$ and IL-1 $\beta$ ), bacteria (Fusobacterium nucleatum, Porphyromonas gingivalis) and fungi (Candida albicans) [12, 18, 20, 28]. In the non-oral epithelium the HBD-2 expression occurs only in the case of inflammation or infection. Possibly the HBD-2 expres- sion in the healthy oral mucosa is stimulated by a constant contact with commensal bacteria [12]. HBD-1 and 2 are present both in healthy gum tissue and in inflamed gingiva, however the inflammation stimulates the expression. Normally HBD-1 and 2 appear in the crevicular epithelium but not in the junctional epithelium $[12,29]$. $\alpha$ and $\beta$ defensins were also detected in the small and large salivary glands and in saliva, although the concentrations of particular defensin' types in saliva may significantly differ in healthy people $[6,25,30]$. Salivary defensins are one of the mechanisms which protect the oral mucosa from the infection; they also act as an indicator for an ongoing inflammation or infection [26]. The poor HBD-2 expression and strong HBD-1 expression was also detected in the healthy teeth pulp [31,32].

The defensin expression in the oral tissues is modified in the presence of pathogenic microorganisms, inflammatory mediators and neoplasmatic lesions. Table 2 illustrates the influence of some infectious oral conditions related with bacterial, viral and fungal etiology together with non-infectious diseases, which include autoimmunologic, inflammatory and malignant conditions on the expression of defensins in the oral environment.

Antibacterial activity, mainly against the aerobic bacteria, is a characteristic feature of $\beta$-defensins [16]. In many studies it was found that the $\beta$-defensin oral expression significantly rises in the presence of bacteria species responsible for the development of periodontitis, which include: Actinomycetes actinomycetemcomitans, Porphyromonas gingivalis and Fusobacterium nucleatum [6, 25, 28, 33] and the induction of the HBD expression occurs in several ways, most probably with MAPK (mitogen-activated protein kinases) or NF- $\kappa \mathrm{B}$ (nuclear factor $\kappa \mathrm{B}$ ) paths $[1,4,14]$. In this light the results of Bissell's et al. research, who did not observe any elevation in the expression of the $\beta$-defensin 1-3 in the inflamed periodontal tissue, while the HBD-3 expression was significantly higher in the healthy controls than in their study group, may be considered surprising [29]. The regulation of the $\beta$-defensins' expression seems to be a very dynamic and variable process, which depends on the periodontitis duration, the composition of the dental plaque and the presence of pro-inflammatory cytokines [34]. Hofman et al. observed significantly increased $\alpha$-defensin (HNP 1-3) concentration in saliva of 25 patients with chronic periodontitis compared to healthy controls [35]. An evident reduction in the $\alpha$-defensin (HNP 1-3) concentration in unstimulated saliva collected from the children with advanced carries was described by Dale et al., which may indicate the role of these compounds in preventing the growth of cariogenic bacteria in oral environment [30]. In Ozturk et al. research a higher predisposition for caries (higher values of DMFT index) were found in people with a particular HBD-1 gene polymorphism (G-20A) [36].

Defensins inhibit the development of pathogenic, enucleated viruses, including Herpes (HSV-1 and HSV-2), 
Table 2. Role of defensins in selected oral mucosa diseases based on literature

\begin{tabular}{|c|c|c|c|c|}
\hline Disease & $\begin{array}{l}\text { Tested } \\
\text { defensin }\end{array}$ & $\begin{array}{l}\text { Defensin's expression } \\
\text { in affected tissues } \\
\text { compared to healthy } \\
\text { tissue }\end{array}$ & $\begin{array}{l}\text { Examined } \\
\text { tissue }\end{array}$ & Author \\
\hline \multirow[t]{2}{*}{ Periodontitis } & HBD 3 & $\downarrow$ & Gingiva & Bissell et al. 2004, USA \\
\hline & HNP 1 & $\uparrow$ & Saliva & Hofman et al. 2008, Poland \\
\hline Carries & HNP 1-3 & $\downarrow$ & Saliva & Dale et al. 2006, USA \\
\hline RRP & HBD 1-3 & $\uparrow$ & $\begin{array}{l}\text { Upper airways } \\
\text { mucous membrane }\end{array}$ & Chong et al. 2006, USA \\
\hline \multirow[t]{2}{*}{$\begin{array}{l}\text { Oral } \\
\text { candidiasis }\end{array}$} & $\begin{array}{l}\text { HNP } 1 \\
\text { HBD } 2\end{array}$ & $\begin{array}{l}\uparrow \\
\uparrow\end{array}$ & Oral mucosa & Sawaki et al. 2002, Japan \\
\hline & $\begin{array}{l}\text { HNP } 1 \\
\text { n }\end{array}$ & $\uparrow$ & Oral mucosa & Ali et al. 2005, Finland \\
\hline \multirow{3}{*}{$\begin{array}{l}\text { Lichen } \\
\text { planus }\end{array}$} & HNP 1 & $\uparrow$ & Saliva & Mizukawa et al. 1999, Japan \\
\hline & & & & Küçükkolbaşı et al. 2011, Turkey \\
\hline & HBD 3 & $\uparrow$ & Oral mucosa & Nishimura et al. 2003, Japan \\
\hline \multirow[t]{2}{*}{ Leukoplakia } & HNP 1 & $\uparrow$ & Saliva & Mizukawa et al. 1999, Japan \\
\hline & $\begin{array}{l}\text { HBD } 1,2 \\
\text { HBD } 3\end{array}$ & $\begin{array}{l}\downarrow \\
\uparrow\end{array}$ & Oral mucosa & Wenghoefer et al. 2008, Germany \\
\hline $\begin{array}{l}\text { Glossitis } \\
\text { ( } \downarrow \text { Fe anaemia) }\end{array}$ & HNP 1 & $\uparrow$ & Saliva & Mizukawa et al. 1999, Japan \\
\hline RAS & HNP 1 & $\uparrow$ & Saliva & Küçükkolbaşı et al. 2011, Turkey \\
\hline $\begin{array}{l}\text { Behçet's } \\
\text { syndrome }\end{array}$ & HNP 1 & $\uparrow$ & Saliva & Küçükkolbaşı et al. 2011, Turkey \\
\hline \multirow[t]{4}{*}{ OSCC } & HBD 1 & $\downarrow$ & Oral mucosa & Wenghoefer et al. 2008, Germany \\
\hline & HBD 1,2 & $\downarrow$ & $\begin{array}{l}\text { OSCC cell lines } \\
\text { (in vitro study) }\end{array}$ & Joly et al. 2009, USA \\
\hline & HBD 1 & $\downarrow$ & & \\
\hline & HBD 2 & $\begin{array}{l}\uparrow \text { (well-differentiated } \\
\text { cornified lesions) } \\
\downarrow \text { (poorly differentiated } \\
\text { lesions) }\end{array}$ & Oral mucosa & Abiko et al. 2000, Japan \\
\hline
\end{tabular}

$R R P$ - recurrent respiratory papillomatosis

$R A S$ - recurrent aphthous stomatitis

OSCC - oral squamous cell carcinoma

CMV, HPV and HIV [2, 16, 37]. The increased expression of HBD-1, 2 and 3 was therefore detected in pathologic lesions of the upper respiratory tract epithelium related with human papilloma virus infection [15], while the expression of HBD-2 and 3 in the oral epithelium was raised in the presence of the HIV $[16,17]$.

Fungal infection with Candida species also influences the defensins' expression in the affected tissues. The mechanism of the defensin antifungal activity has not been fully understood so far; similarly like with the antibacterial properties, the efficacy of the action may differ depending on the surrounding conditions, which include for example the concentration of $\mathrm{Ca}^{2+}, \mathrm{Mg}^{2+}$ ions and salts [38]. According to Feng et al., defensins inhibit the Candida cells adhe- sion to the epithelium and they damage the fungal cellular membrane. Their expression significantly increases after the contact with pathogenic, hyphal mycelium [39]. In the immunohistochemical analysis of the buccal mucosa specimens received from patients with oral candidiasis, Sawaki et al. observed significantly increased expression of HBD-2 in pathologically changed tissue regions in comparison to healthy areas [40], which remains consistent with Dunsche et al. conclusions [31]. According to Abiko et al., the expression of that defensin becomes upregulated after a certain period of the Candida infection. A transformation from a blastosporic into a hyphal form seems to play an important role in the modification of the defensins' expression. As the hyphal invasion progress, the HBD-2 expres- 
sion becomes reduced [37]. Also the $\alpha$-defensins participate in the antifungal response. In the oral mucosa bioptates received from the patients with chronic hyperplastic candidiasis Ali et al. observed a high concentration of the HNP-1 $\alpha$-defensin, produced by neutrophils. Especially high concentration of the HNP-1-containing neutrophils was found in strongly infected tissue specimens, where the neutrophils formed the microabscess-like clusters. Apart from a direct effect on fungal hyphae, which leads to the Candi$d a$ cell growth inhibition or death, $\alpha$-defensins also create a protective barrier in the superficial layers of epithelium, which prevents the pathogen penetration into the deeper lying tissues [41]. In the observations of Sawaki et al. a high concentrations of HNP-1 were found in Candida infected tissues, while the defensin was not detected at all in the control healthy tissue specimens [40].

The increased expression of some defensins was also observed in the inflammatory conditions of the oral cavity not related with the infection, which may be related with the presence of pro-inflammatory cytokines and their inductive effect on the defensin expression. It was observed that TNF- $\alpha$ stimulates the expression of HBD-2 gene, while $\gamma$-interferon promotes the production of HBD-3 [42]. In the immunohistochemic studies of the oral mucosa specimens received from patients with lichen planus a high concentration of HBD-2 was observed, similarly like in conjunctiva specimens obtained from the patients with Sjögren syndrome [37]. The increased expression of HBD-3 was also detected in lichen planus and leukoplakia; this observation was especially evident in lichen planus patients [42]. The increased HBD-3 expression in leukoplakia was also described by Wenghoefer et al., who simultaneously observed the significant limitation in the expression of HBD-1 and HBD-2 in diseased tissues in comparison to healthy mucosa specimens [43]. Elevated salivary HNP-1 concentrations compared to healthy volunteers were described in patients with leukoplakia, lichen planus and glossitis related with the iron deficiency anemia [44]. Significantly increased HNP-1 concentrations in comparison to health controls were observed in saliva collected from the patients with lichen planus, recurrent aphthous stomatitis and Behçet's syndrome. In the examined subjects the defensin concentrations were also elevated during the exacerbations in comparison to the periods of their disease remission [45].

Some modifications in the HBD-1' and 2' expression occur also in the planoepithelial oral cancer, the studies' results however are inconsistent and not very conclusive. In the observations of Abiko et al. the increased expression of HBD-2 and decreased expression of HBD-1 were found in highly-differentiated, keratinized lesions, while in poorly differentiated, squamous call carcinomas the expression of HBD-2 was not detected at all [33]. Malignant neoplasms are very often accompanied by the inflammatory reaction, which, according to Abiko, may additionally stimulate the
HBD-2 expression in some oral neoplasms. The results of the in vitro cell lines observations, derived from oral squamous cell carcinomas (OSCC) confirmed that the expression of HBD-2 was related with the level of epithelial keratinization and increased in more keratinizated tissues [33, 37]. Meanwhile Joly et al. described a significant loss of HBD-1 and HBD-2 expression in the cell lines derived from the oral squamous cell carcinoma together with the decreased response to inducing factors like TNF- $\alpha$, IFN- $\gamma$ and IL-1 $\beta$ in comparison to a normal tissue [46]. Very significant limitation in HBD-1 expression in squamous cell carcinoma was also found by Wenghoefer et al., which may indicate the role of this defensin in the malignant transformation of some benign conditions [37, 43].

\section{Summary}

Potentially, due to their multidirectional antimicrobial and immunomodulating properties, defensins could be used in the treatment of several infections and inflammatory disorders. The increasing bacterial antibiotic resistance creates a necessity to search new, more effective antibacterial agents. Clinical research on developing drugs based on synthetic antimicrobial peptides or modulating their expression has already been started worldwide [25, 42, 44]. Abiko et al. suggest the use of $\beta$-defensin-based agents in the treatment of ulcerative oral conditions, including RAS, pemphigoid, pemphigus and ulcerative stomatitis. Modification of the defensin gene expression may also influence the risk of malignant transformation in pre-cancerous lesions [11]. However, despite the multidirectional, multi-centered studies, the role of defensins in the state of health and disease still remains not clearly defined. Their antimicrobial and immunomodulating properties raise a great interest and create potential options for their utilization in the treatment of infectious and inflammatory disease. Simultaneously, their negative role in the etiopathogenesis of some disorders, especially those with auto-immunologic background needs to be considered.

\section{References}

1. Kaiser V, Diamond G (2000): Expression of mammalian defensin genes. J Leukoc Biol 68: 779-784.

2. Niedźwiedzka-Rystwej P, Deptuła W (2008): Defensins: an important innate element of the immune system in mammals. Postepy Hig Med Dosw 62: 524-529.

3. Witkowska D, Bartyś A, Gamian A (2008): Defensyny i katelicydyny jako naturalne antybiotyki peptydowe. Postepy Hig Med Dosw 62: 694-707.

4. Schneider JJ, Unholzer A, Schaller M, et al. (2005): Human defensins. J Mol Med (Berl) 83: 587-595.

5. Wierchuła BE, Tustanowski JP, Martirosian G (2006): Peptydy antydrobnoustrojowe. Wiad Lek 59: 542-547.

6. Mathews M, Jia HP, Guthmiller JM, et al. (1999): Production of $\beta$-defensin antimicrobial peptides by the oral mucosa and salivary glands. Infect Immun 67: 2740-2745. 
7. Niedźwiedzka-Rystwej P, Mękal A, Deptuła W (2010): Peptydy przeciwdrobnoustrojowe - ważny element odporności naturalnej. Alerg Astma Immun 15: 35-41.

8. De Smet K, Contreras R (2005): Human antimicrobial peptides: defensins, cathelicidins and histatins. Biotechnol Lett 27: 1337-1347.

9. Tollin M, Bergman P, Svenberg T, et al. (2003): Antimicrobial peptides in the first line deffence of human colon mucosa. Peptides 24: 523-530.

10. Cunliffe RN (2003): $\alpha$-defensins in the gastrointestinal tract. Mol Immunol 40: 463-467.

11. Hazlett L, Wu M (2011): Defensins in innate immunity. Cell Tissue Res 343: 175-188.

12. Dale BA, Krisanaprakornkit S (2001): Defensin antimicrobial peptides in the oral cavity. J Oral Pathol Med 30: 321-327.

13. Oppenheim JJ, Biragyn A, Kwak LW, Yang D (2003): Roles of antimicrobial peptides such as defensins in innate and adaptive immunity. Ann Rheum Dis 62 Suppl 2: ii17-ii21.

14. Boman HG (2003): Antimicrobial peptides: basic facts and emerging concepts. J Intern Med 254: 197-215.

15. Chong KT, Xiang L, Wang X, et al. (2006): High level expression of human epithelial $\beta$-defensins (hBD-1, 2 and 3) in papillomavirus induced lesions. Virol J 3: 75.

16. Dale BA, Fredericks LP (2005): Antimicrobial peptides in the oral environment: expression and function in health and disease. Curr Issues Mol Biol 7: 119-134.

17. Diamond G, Beckloff N, Ryan LK (2008): Host defense peptides in the oral cavity and the lung: similarities and differences. J Dent Res 87: 915-927.

18. Weinberg A, Krisanaprakornkit S, Dale BA (1998): Epithelial antimicrobial peptides: review and significance for oral applications. Crit Rev Oral Biol Med 9: 399-414.

19. Doss M, White MR, Tecle T, Hartshorn KL (2010): Human defensins and LL-37 in mucosal immunity. J Leukoc Biol 87: 79-92.

20. Krisanaprakornkit S, Weinberg A, Perez CN, Dale BA (1998): Expression of the peptide antibiotic human $\beta$-defensin 1 in cultured gingival epithelial cells and gingival tissue. Infect Immun 66: 4222-4228.

21. Wehkamp J, Schmid M, Fellermann K, Stange EF (2005): Defensin deficiency, intestinal microbes, and the clinical phenotypes of Crohn's disease. J Leukoc Biol 77: 460-464.

22. Ramasundara M, Leach ST, Lemberg DA, Day AS (2009): Defensins and inflammation: the role of defensins in inflammatory bowel disease. J Gastroenterol Hepatol 24: 202-208.

23. Fellermann K, Stange DE, Schaeffeler E, et al. (2006): A chromosome 8 gene-cluster polymorphism with low human betadefensin 2 gene copy number predisposes to Crohn disease of the colon. Am J Hum Genet 79: 439-448.

24. Schaefer AS, Richter GM, Nothnagel M, et al. (2010): A 3' UTR transition within DEFB1 is associated with chronic and aggressive periodontitis. Genes Immun 11: 45-54.

25. Dunsche A, Açil Y, Siebert R, et al. (2001): Expression profile of human defensins and antimicrobial proteins in oral tissues. J Oral Pathol Med 30: 154-158.

26. Abiko Y, Nishimura M, Kaku T (2003): Defensins in saliva and the salivary glands. Med Electron Microsc 36: 247-252.

27. Dale BA, Kimball JR, Krisanaprakornkit S, et al. (2001): Localized antimicrobial peptide expression in human gingiva. J Periodontal Res 36: 285-294.

28. Yin L, Chino T, Horst OV, et al. (2010): Differential and coordinated expression of defensins and cytokines by gingival epithelial cells and dendritic cells in response to oral bacteria. BMC Immunol 11: 37.

29. Bissell J, Joly S, Johnson GK, et al. (2004): Expression of betadefensins in gingival health and in periodontal disease. J Oral Pathol Med 33: 278-285.

30. Dale BA, Tao R, Kimball JR, Jurevic RJ (2006): Oral antimicrobial peptides and biological control of caries. BMC Oral Health 6: S13.

31. Dunsche A, Açil Y, Dommisch H, et al. (2002): The novel human beta-defensin-3 is widely expressed in oral tissues. Eur J Oral Sci 110: 121-124.

32. Dommisch H, Winter J, Açil Y, et al. (2005): Human $\beta$ defensin (hBD-1, -2) expression in dental pulp. Oral Microbiol Immunol 20: 163-166.

33. Abiko Y, Suraweera AK, Nishimura M, et al. (2001): Differential expression of human $\beta$-defensin 2 in keratinized and non-keratinized oral epithelial lesions; immunohistochemistry and in situ hybridization. Virchows Arch 438: 248-253.

34. Gomes Pde S, Fernandes MH (2010): Defensins in the oral cavity: distribution and biological role. J Oral Pathol Med 39: 1-9.

35. Hofman J, Szkaradkiewicz AK, Karpiński TM (2008): Evaluation of defensin (HNP 1-3) presence in saliva and serum of patients with chronic periodontitis. Czas Stomatol 61: 881-885.

36. Ozturk A, Famili P, Vieira AR (2010): The antimicrobial peptide DEFB1 is associated with caries. J Dent Res 89: 631-636.

37. Abiko Y, Saitoh M, Nishimura M, et al. (2007): Role of $\beta$-defensins in oral epithelial health and disease. Med Mol Morphol 40: 179-184.

38. Vylkova S, Nayyar N, Li W, Edgerton M (2007): Human $\beta$-defensins kill Candida albicans in an energy-dependent and salt-sensitive manner without causing membrane disruption. Antimicrob Agents Chemother 51: 154-161.

39. Feng Z, Jiang B, Chandra J, et al. (2005): Human $\beta$-defensins: differential activity against candidal species and regulation by Candida albicans. J Dent Res 84: 445-450.

40. Sawaki K, Mizukawa N, Yamaai T, et al. (2002): Immunohistochemical study on expression of $\alpha$-defensin-2 in human buccal epithelia with candidiasis. Oral Dis 8: 37-41.

41. Ali A, Niissalo S, Hietanen J, et al. (2005): Expression of alpha-defensin-1 in chronic hyperplastic candidosis. J Oral Pathol Med 34: 347-351.

42. Nishimura M, Abiko Y, Kusano K, et al. (2003): Localization of human $\beta$-defensin 3 mRNA in normal oral epithelium, leukoplakia, and lichen planus: an in situ hybridization study. Med Electron Microsc 36: 94-97.

43. Wenghoefer M, Pantelis A, Dommisch H, et al. (2008): Decreased gene expression of human $\beta$-defensin- 1 in the development of squamous cell carcinoma of the oral cavity. Int J Oral Maxillofac Surg 37: 660-663.

44. Mizukawa N, Sugiyama K, Ueno T, et al. (1999): Defensin-1, an antimicrobial peptide present in the saliva of patients with oral diseases. Oral Dis 5: 139-142.

45. Küçükkolbaşi H, Küçükkolbaşi S, Dursun R, et al. (2011): Determination of defensin HNP-1 in human saliva of patients with oral mucosal diseases. J Immunoassay Immunochem 32: 284-295.

46. Joly S, Compton LM, Pujol C, et al. (2009): Loss of human $\beta$-defensin 1, 2 and 3 expression in oral squamous cell carcinoma. Oral Microbiol Immunol 24: 353-360. 